\title{
Mudskippers in the Mekong Delta might tell us something about vertebrate transition to land?
}

\author{
Atsushi Ishimatsu ${ }^{1,2 *}$ \\ ${ }^{1}$ Organization for Marine Science and Technology, Nagasaki University, 1551-7 Tairamachi, Nagasaki 851-2213, \\ Japan
}

${ }^{2}$ JICA CTU Office, Can Tho University, Vietnam

Keywords: Vertebrates, Freshwater environments, P. septemradiatu, Atmospheric salinity

Accepted on June 05, 2020

\section{Commentary}

Rise of vertebrates from water to land, which seems to be occurred in the mid to late Devonian Period (about 390 to 360 million years ago), shows one of the most crucial events throughout the existence of life [1]. There are many longstanding debates about emergence of vertebrates in the Paleozoic from marine environment or freshwater environments [2-6]. Through our four-year survey in the field in the place called Mekong Delta which is situated in Vietnam, we explored mudskippers a special species, Periophthalmodon septemradiatus, which inhabits the littoral zones in brackish waters near the coast of fully freshwater areas $150 \mathrm{~km}$ from the river mouth along the Mekong River [7]. Mudskippers which are amphibious gobies which usually inhabits intertidal mudflats from estuaries, subtropical coasts and tropical coasts and shows behavioral, physiological and morphological adaptations of life on land [8]. The most terrestrial fishes named Periophthalmodon septemradiatus are living today. During the period of our field survey, we have not seen any $P$. septemradiatus ventures into water. The substantial portal of gut content of this fish is constituted by ants, further supporting the high terrestriality of the fish.

P. septemradiatus spawns eggs within a burrow excavated in the river banks of both freshwater and brackish environments. The fish which is of smaller is collected up to the upstream habitat limit were juveniles shortly after starting an amphibious life. These are the evidences which suggest that it reproduces both in freshwater and brackish water environments. In contrast, otolithSr:Ca ratio of fish collected in both environments showed values of $7-8$ in the otolith core, indicating larval hatching only in brackish water. Our current hypotheses are [1] freshwater larvae hatches which migrate downstream to brackish/marine waters and migrate back to the upstream reaches, and the high $\mathrm{Sr}$ :Ca ratio in the otolith does not somehow reflect atmospheric salinity $[2,9]$ larvae that hatch in freshwater are abortive and those that hatch in brackish/ marine waters recruit to the entire distribution range and thus constitute the exclusive source of all the populations. Another perplexing fact is that our preliminary incubation of fertilized eggs from field burrows demonstrated that the larvae can hatch in salinities from 0 to $16-17$, but hardly in 34 . Larvae hatched at a much earlier developmental stage than other mudskippers [10], but is quite similar to the larvae of sicydiine gobies [11-13], which show amphidromous migration with long oceanic larval duration (80-220 days) $[14,15]$, possibly an adaptation to life in instable conditions of insular streams [16]. Our further studies are needed to disclose the occurrence of larval in coastal wa and fluvial waters. In context to this, larval rearing is needed to establish the correlation between the concentrations of $\mathrm{Ca}$ and $\mathrm{Sr}$ in otolith and ambient water $\mathrm{Sr}: \mathrm{Ca}$ ratio; the development rate at temperatures prevailing in the region of Mekong River; and tolerance of salt in juveniles and larvae which are under controlled conditions.

The facts that $P$. septemradiatus is greatly terrestrial and that the fish inhabits wide reaches from brackish to completely fresh waters render the species a suitable model for the investigation of how animal's body anatomy, physiology and ecology are to be modified during emersion to land from waters of different salinities [17].

\section{References}

1. Clack JA. Gaining Ground: The Origin and Evolution of Tetrapods, Second edition. Bloomington. Indiana University Press. 2012.

2. Clack JA. Devonian climate change, breathing, and the origin of the tetrapod stem group. Integr Comp Biol. 2007; 47:510-523.

3. Niedźwiedzki G, Szrek P, Narkiewicz K, et al. Tetrapod trackways from the early Middle Devonian period of Poland. Nature. 2010; 463: 43-48.

4. Goedert J, Lécuyer C, Amiot R, et al. Euryhaline ecology of early tetrapods revealed by stable isotopes. Nature. 2018;558:68-72.

5. Balbus SA, Dynamical, biological and anthropic consequences of equal lunar and solar angular radii. Proc $\mathrm{R}$ Soc. A 2014; 470: 20140263.

6. Retallack GJ, Woodland hypothesis for Devonian tetrapod evolution. J Geol. 2011; 119: 235-258.

7. Mai VH, Tran XL, Dinh QM, et al. Land invasion by the mudskipper, Periophthalmodonseptemradiatus, in fresh and saline waters of the Mekong River. Sci Rep. 2019; 9: 14227.

8. Jaafar A, Murdy EO. Fishes Out of Water: Biology and Ecology of Mudskippers. Boca Raton:CRC Press. 2017.

9. Correia AT, Antunes C, Isidro EJ, et al. Changes in otolith microstructure and microchemistry during larval development of the European conger eel (Conger conger). Mar Biol. 2003; 142: 777-789. 
Citation: Ishimatsu A. Mudskippers in the Mekong Delta might tell us something about vertebrate transition to land? J Fish Res 2020;4(2): 5-6.

10. Tsuhako Y, Ishimatsu A, Takeda T, et al. The eggs and larvae of the giant mudskipper, Periophthalmodonschlosseri, collected from a mudflat in Penang, Malaysia. Ichthyol Res. 2003; 50: 178-181.

11. Dôtu Y, Mito S. Life history of a Gobioid fish, Sicydiumjaponicum TANAKA. Sci Bull FacAgr Kyushu Univ. 1955; 15: 213-221.

12. Ellien C, Werner U, Keith P. Morphological changes during the transition from freshwater to sea water in an amphidromous goby, Sicyopteruslagocephalus (Pallas 1770) (Teleostei). Ecol Freshw Fish. 2016; 25: 48-59.

13. Yamasaki N, Kondo M, Maeda K, et al. Reproductive biology of three amphidromous gobies, Sicyopterusjaponicus, Awaousmelanocephalus, and Stenogobius sp., on Okinawa Island. Cybium. 2011; 35: 345-360.

14. Lord C, Brun C, Hautecœur M, et al. Insights on endemism: comparison of the duration of the marine larval phase estimated by otolith microstructural analysis of three amphidromousSicyopterus species (Gobioidei: Sicydiinae) from Vanuatu and New Caledonia. Ecol Freshw Fish. 2010; 19: 26-38.
15. Iida $\mathrm{M}$, Watanabe $\mathrm{S}$, Tsukamoto $\mathrm{K}$. Oceanic larval duration and recruitment mechanism of the amphidromous fish Sicyopterusjaponicus (Gobioidei: Sicydiinae). Reg Stud Mar Sci. 2015; 1: 25-33.

16. Keith P. Biology and ecology of amphidromousGobiidae of the Indo - Pacific and the Caribbean regions. J Fish Biol. 2003; 63: 831-847.

17. Ishimatsu A, Gonzales TT. Mudskippers: Front runners in the modern invasion of land. In: Patzner R, Van Tassell JL, Kovačić M, Kapoor BG. (eds) The Biology of Gobies, Enfield: Science. pp. 609-638.

*Correspondence to

Atsushi Ishimatsu

Organization for Marine Science and Technology,

Nagasaki University

Tairamachi, Nagasaki, Japan

E-mail: a-ishima@nagasaki-u.ac.jp 